\title{
PERICIA CONTABLE Y LAVADO DE ACTIVOS EN COOPERATIVAS DE AHORRO Y CRÉDITO DEL PERÚ
}

\author{
ACCOUNTING EXPERTISE AND MONEY LAUNDERING IN SAVINGS AND CREDIT \\ COOPERATIVES OF PERU
}

\author{
JuLıo Gómez MÉNDEZ \\ Universidad Nacional de San Cristóbal de Huamanga \\ Ayacucho, Perú \\ ORCID: http://orcid.org/0000-0002-0379-0349 \\ Correo electrónico: gomezmjulio@hotmail.com
}

Nerio Janampa Acuña

Universidad Nacional Mayor de San Marcos

Lima, Perú

ORCID: http://orcid.org/0000-0003-0252-2649

\section{RESUMEN}

Objetivo: Desarrollar una investigación de tipo empírica sobre pericia contable y lavado de activos en Cooperativas de Ahorro y Crédito del Perú. Método: La investigación es de tipo descriptiva y su diseño es no experimental, ya que no se manipuló variable alguna para condicionar los resultados de la investigación, solo se observó el fenómeno de lavado de activos en el seno de las Cooperativas, tal como se presenta en su contexto natural. Para cumplir el objetivo se ha realizado encuestas a Cooperativas de Ahorro y Crédito del Perú que se encuentran activas. Resultados: Los encuestados manifiestan que el $60,12 \%$ de las Cooperativas de Ahorro y Crédito del Perú no han implementado el sistema de prevención de lavado de activos y financiamiento del terrorismo. Conclusiones: Los resultados sirven de base para nuevos estudios ligados a la temática de pericia contable y lavado de activos, además se busca la implementación del sistema de prevención del lavado de activos y financiamiento del terrorismo.

Palabras clave: Pericia; contable; lavado; activos; financiamiento ilícito.

\begin{abstract}
Objective: Develop an empirical investigation on accounting expertise and money laundering in Savings and Credit Cooperatives of Peru. Method: The research was descriptive because it used bibliographic references to develop the introduction. The research design was non-experimental, since the independent variable was not manipulated to see its effect on the dependent variable, only the phenomenon of asset laundering was observed within the Cooperatives, as presented in its natural context. To meet the objective, surveys have been carried out on Savings and Credit Cooperatives of Peru that are active Results: The respondents state that $60.12 \%$ of the Savings and Credit Cooperatives of Peru have not implemented the money laundering and terrorist financing prevention system. Conclusions: The results serve as the basis for new studies linked to the subject of accounting expertise and money laundering, also it searches the implementation of the system of prevention of money laundering and terrorist financing.
\end{abstract}

Keywords: Expertise; accounting; laundering; assets; financing and illegal.

(c) Los autores. Este artículo es publicado por la Revista Quipukamayoc, Universidad Nacional Mayor de San Marcos. Este es un artículo de acceso abierto, distribuido bajo los términos de la Licencia Creative Commons Atribución-NoComercial-Compartirlgual 4.0 Internacional.(http://creativecommons.org/licenses/by-nc-sa/4.0/), que permite el uso no comercial, distribución y reproducción en cualquier medio, siempre que la obra original sea debidamente citadas. 


\section{INTRODUCCIÓN}

Durante los últimos 10 años se ha incrementado considerablemente las Cooperativas de Ahorro y Crédito en el Perú con dos propósitos fundamentales: captar los recursos financieros de los socios ofreciendo, por los depósitos a plazo fijo, tasas de interés superiores a lo establecido por la Superintendencia de Banca, Seguros y AFP (SBS), independientemente a los obsequios que consiste en artefactos electrodomésticos, bicicletas, motos, laptops y sorteo de automóviles, promociones que resultan atractivos y convincentes para muchos ciudadanos; y legalizar el dinero sucio proveniente del narcotráfico.

El peritaje contable es un documento de análisis de los procesos contables que se realiza para tener nociones claras del procedimiento de la contabilidad de las entidades del Estado. Este proceso es direccionado por un contador público y está inmerso en un proceso judicial con la intención de brindarle al juzgado información detallada y especifica de la manera en que los servidores públicos han administrado el dinero del Estado para realizar las funciones que se les ha encomendado, de acuerdo a los cargos asumidos en un determinado tiempo y contexto.

El peritaje relacionado a la contabilidad es una forma de estudiar los procesos que asume un encargado sobre la administración pública y que el juez está en la disposición de emplear la información brindada por el perito para dar un veredicto justo, ya que están respaldados por la experiencia del especialista. Es así que, al finalizar su trabajo, realiza una confrontación entre los resultados que obtuvo con la información que fue presentada como legítima en un proceso legal. El producto de un peritaje debe cumplir con los estándares requeridos para ser un insumo legal irrefutable ante la acusación hacia una persona que ha incumplido con la honestidad en la administración pública.

Sobre la esencialidad del peritaje contable, Carnelutti (1980) afirma que:

Con la mejora de la tecnología el trabajo de los peritos se sume en dificultades que los expertos deben saber afrontar; por ello, es vital que la labor del proceso de peritaje sea lo más certero posible, ya que están basado en requisitos que los convierte en información fiable y que sirve de insumo para que un juez pueda administrar la justicia de manera adecuada y respaldado por la declaración de los expertos en esta materia (p. 67).

Continuando con los aportes, se puede plantear la vitalidad e importancia que asume el peritaje dentro de los procesos relacionados con la justicia, donde un juez asume las decisiones basándose en la información brindada por el perito, quien resulta ser el experto, cuya declaración es un indicador de certeza para el juez. Además, esto es esencial, ya que ayuda a esclarecer los procesos contables con la intención de buscar la transparencia administrativa de los fondos del Estado.

Al respecto, Ruiz (2013) postuló que:

El peritaje es la pericia en acción por su naturale$z a$; es la actividad que realiza el perito $y$, que para distinguirse de otras similares extraprocesales que dan origen a informes técnicos y no a dictámenes, es indispensable, sine qua non, que sea producto de un mandato o encargo judicial. Será también por mandato fiscal durante la investigación preparatoria que tendrá a su cargo la respectiva actuación de las pruebas (p.42).

Ramírez (1992) refirió que:

La pericia contable debe ser concebida más allá de otros aspectos, como el aporte de nuestra profesión para garantizar la acertada decisión de parte del juez y/o fiscal. La participación del contador público como perito judicial $y /$ o fiscal ha sumado cada vez mayor importancia en las controversias de tipo civil o penal, a lo que se incluye el aspecto tributario. La labor auxiliar de la justicia desempeñada por el perito contable demanda de los profesionales una codificación de sus principales aspectos legales, técnicos y éticos inclusive lo que, sumado a la carencia de bibliografía y una adecuada concepción de su naturaleza, hace importante y necesaria un estudio que nos permita entender este campo de desarrollo del contador público (p. 7).

El trabajo del perito contable es dedicarse al análisis de procesos contables, dirigido por un contador público colegiado, quien realizará un informe final para que le sirva al juez en las investigaciones que se desarrollan sobre una persona que ha estado encargada de la administración de los fondos del Estado y que se encuentra inmersa en proceso judicial.

De esta manera, Ugarte (2014) indicó que el lavado de activos se refiere a transacciones mediante los cuales se pretende ocultar el origen del dinero, empleando diversos mecanismos para reemplazarlo o transformarlo a recursos económicos legales. Se inyecta el dinero al negocio a modo de inversión para que se convierta en dinero lícito.

Asimismo, Armienta, Goite, Medina, Gambino y García (2015) sostienen que el blanqueamiento del dinero es el procedimiento mediante el cual se intenta borrar el origen turbio del dinero o de los bienes obtenidos de prácticas criminales o de estafas, como por ejemplo el contraban- 
do, corrupción, extorsión u otras actividades que causan daño al sistema económico del país. La meta fundamental de este proceso es mostrar que el dinero ingresado se ha obtenido de actividades honestas para que puedan circular sin problema en el sistema financiero y que su origen desaparezca para evitar problemas legales.

De igual forma, según Cano (2015) limpiar activos es realizar gestiones que hagan ver que el dinero inyectado a un establecimiento o manejado por una persona natural, logre ser puesta en lugares donde no detecten su procedencia y después de un tiempo de haber realizado la inyección financiera ilícita, se pretenda introducirlo al sistema financiero como dinero lícito.

Rolando (2005) precisó que:

El blanqueamiento de activos atraviesa por distintas fases, las que tienen como objetivo maquillar el usufructo del mismo, mediante transacciones que realizan personas naturales o jurídicas, estos procesos se modifican cada cierto tiempo para evitar ser expuestos, realizan sus actos criminales haciendo uso de las entidades financieras y se apoyan con la tecnología para lograr su evasión, extendiendo su dominio a nivel mundial (p. 68).

Se entiende que el blanqueado de activos es considerado un delito, que se relaciona con brindar un aspecto de origen lícito a ciertos bienes - dinerarios o no, que resultan ser lucros obtenidos en base a faltas graves, entre ellos se puede referir: narcotráfico, trata de personas, corrupción, sobornos y otros. Según menciona la oficina de las Naciones Unidas que está encargada de la lucha contra los delitos citados, ya que daña a los seres humanos y a las personas jurídicas. Constituye un atentado hacia la seguridad y el orden dentro del país. Aquellos que se enriquecen de manera ilícita, son individuos que mellan el futuro, porque usan estos fondos para seguir financiando nuevos delitos; dentro de las faltas cometidas por gente inescrupulosa está en dañar a las empresas pequeñas, promoviendo la competencia desleal, ya que su único interés está en blanquear el dinero a través de la simulación de negocios, buscando testaferros a quienes involucran para despistar a las autoridades. La oficina encargada de Asuntos Antinarcóticos que opera desde la Embajada de los Estados Unidos, cuya sede en Perú, lleva a cabo acciones que apoyan a las entidades correspondientes (Ramírez y Ruiz, 2018).

Las fases esenciales del lavado de activo son: colocación, el encargado del hecho delictivo inyecta el dinero en empresas de cualquier rubro, constantemente los fondos son transferidos a entidades circundantes al lugar de las actividades delictivas para realizar seguimiento del fondo; transformación o intercalación, acción en la cual el dinero ha sido invertido en una empresa que está dentro del ámbito de la formalidad, el lavador realiza un conjunto de acciones con el activo para desligarlos de su origen ilícito. Consiste en separar, transformar y disfrazar la masa de dinero ilícito en dinero lícito, a través de transacciones financieras, tales como depósitos a plazo fijo, compra de títulos, acciones, transferencia a cuentas bancarias ubicadas en el exterior, etc. Integración, se inyecta el dinero ilícito a la empresa formal, los encargados de conducir el negocio deben realizar actividades de inversión con el dinero para que sea considerado como dinero lícito y pueda circular sin problemas en los sistemas financieros. Es la reinserción de los fondos ilegales en la economía, es el desplazamiento de los fondos hacia empresas o negocios legítimos encargados de incorporarlos con bienes obtenidos lícitamente. (Huayllani, 2016).

Lamas (2015) expresó que:

El efecto económico del lavado de dinero es una de las consecuencias más dañinas del blanqueamiento de dinero y se da en el sector privado. Por lo general, los participantes emplean como fachada a las compañías que mezclan las utilidades del dinero turbio con aquellas obtenidas con los fondos lícitos, con el objetivo de maquillar el origen del activo ilícito (p. 35).

De esta manera, por la pérdida del control de la política económica, Michael Camdessus, ex director gerente del FMI, brindo datos estadísticos sobre la envergadura del lavado de activos que oscila entre el $2 \%$ y $5 \%$ del PB mundial, monto que trasciende los 600000 millones de dólares.

\section{MATERIALES Y MÉTODOS}

En este sentido, el tipo de investigación utilizada fue básica porque se utilizaron los estudios teóricos y normativos de lavado de activos para realizar el trabajo de campo, mediante la aplicación de cuestionarios y encuestas. De la misma forma, el nivel de investigación fue descriptiva por haber utilizado referencias bibliográficas para el desarrollo del marco teórico. El diseño de investigación fue no experimental, dado que no se manipuló variable alguna para condicionar los resultados de la investigación, solo se observó el fenómeno de lavado de activos en el seno de las Cooperativas de Ahorro y Crédito del Perú, tal como se presenta en su contexto natural.

De esta manera, la población comprendió a 163 Cooperativas de Ahorro y Crédito activas en el Perú, de los cuales 82 son Cooperativas activas afiliadas a Federación de Cooperativas y Ahorro y Crédito (FENACREP) y 81 son Cooperativas activas no afiliadas al FENACREP. Al mismo tiempo, para la aplicación de las encuestas, se ha utilizado las 163 Cooperativas de Ahorro y Crédito del Perú activas. 


\section{RESULTADOS}

La aplicación de las encuestas arrojó los siguientes resultados que serán descritos, a través de cuadros e imágenes.

En la Tabla 1 se muestra que del 100\% de los encuestados, el $60,12 \%$, que equivale a 98 de los encuestados, señalan que no se ha implementado el sistema de prevención de lavado de activos, el 30,6\% que equivale a 49 encuestados dicen sí, han implementado el sistema de prevención de lavado de activos y financiamiento del terrorismo y el $9,82 \%$ que equivale a 16 encuestados no opinan sobre la implementación del sistema de prevención de lavado de activos. Es decir, la Cooperativa no toma medidas en implementar el sistema de prevención de lavados activos y financiamiento de terrorismo.

Tabla 1

Implementación del Sistema de Prevención de lavado de activos y financiamiento del terrorismo

\begin{tabular}{ccc}
\hline Respuestas & $\begin{array}{c}\text { Cantidad de } \\
\text { personas }\end{array}$ & $\begin{array}{c}\text { Cantidad en } \\
\text { porcentaje }\end{array}$ \\
\hline Sí & 49 & 30,06 \\
No & 98 & 60,12 \\
No opina & 16 & 9,82 \\
\hline Total & 163 & $100 \%$
\end{tabular}

Fuente: Elaboración propia

En la Tabla 2 se percibe que, el 57,67\% que equivale a 94 encuestados indican que la falta de supervisión de parte de FENACREP es una de las causas, mientras que el 35,58\% de encuestados muestran que la inexperiencia del personal en previsión del lavado de activos (LA) y financiamiento de terrorismo (FT) es una de las causas y de la misma forma, el 6,75\% que equivale a 11 encuestados manifiestan que el control interno débil de ingreso de efectivo es una de las causas. Por lo tanto, la causa importante de lavado de dinero es por la falta de supervisión de FENACREP, esto se debe a la mínima intervención del control interno.

Tabla 2

Causas importantes del lavado de dinero

\begin{tabular}{lcc}
\hline \multicolumn{1}{c}{ Respuestas } & $\begin{array}{c}\text { Cantidad de } \\
\text { personas }\end{array}$ & $\begin{array}{c}\text { Cantidad en } \\
\text { porcentaje }\end{array}$ \\
\hline $\begin{array}{l}\text { Falta de supervisión de parte } \\
\text { de FENACREP }\end{array}$ & 94 & 57,67 \\
$\begin{array}{l}\text { Control interno débil de Ingre- } \\
\text { so de efectivo }\end{array}$ & 11 & 6,75 \\
$\begin{array}{l}\text { Inexperiencia del personal en } \\
\text { prevención LA y FT }\end{array}$ & 58 & 35,58 \\
\hline $\begin{array}{l}\text { Total } \\
\text { Tot }\end{array}$ & 163 & $100 \%$
\end{tabular}

Fuente: Elaboración propia
En la Tabla 3 se observa que el 44,79\% que equivale a 73 encuestados señalan que los políticos corruptos son los actores que dirigen el lavado activo de dinero, el 31,90\% que equivale a 52 encuestados manifiestan que los narcotraficantes son los actores de lavado de dinero y el 23,31\% que equivale a 38 encuestados expresan que los funcionarios corruptos son los actores de lavado de dinero. Es decir, por falta de participación de la política de control económica de los mercados financieros.

Tabla 3

Actores esenciales que promueven el lavado de dinero

\begin{tabular}{lcc}
\hline Respuestas & $\begin{array}{c}\text { Cantidad de } \\
\text { personas }\end{array}$ & $\begin{array}{c}\text { Cantidad en } \\
\text { porcentaje }\end{array}$ \\
\hline Los políticos corruptos & 73 & 44,79 \\
Los funcionarios corruptos & 38 & 23,31 \\
Los narcotraficantes & 52 & 31,90 \\
\hline Total & 163 & $100 \%$
\end{tabular}

Fuente: Elaboración propia

El 44,79\% de personas opinan que los actores esenciales que promueven el blanqueado de activos, suelen ser los políticos corruptos. Por esta razón, se entiende que el blanqueado de dinero es: brindarle un aspecto legal al dinero, cuyo origen han sido actividades ilegales, creando procesos falsos que le sirven para justificar la presencia de dinero sucio.

En la tabla 4, se visualiza que el $46,01 \%$ que equivale a 75 encuestados dicen que la debilidad de la integridad de los mercados financieros es uno de sus efectos de lavado de activos, el 34, 97\% que equivale a 57 encuestados manifiestan que la pérdida de las rentas públicas es uno de los principales efectos de lavado de activo y el 19,02\% de los encuestados opinan que la pérdida de control de la política económica es uno de los principales efectos de lavado de activos. Es decir, se debe implementar un control de la política económica.

Tabla 4

Principales efectos de lavado de activos

\begin{tabular}{lcc}
\hline Respuestas & $\begin{array}{c}\text { Cantidad de } \\
\text { personas }\end{array}$ & $\begin{array}{c}\text { Cantidad en } \\
\text { porcentaje }\end{array}$ \\
\hline $\begin{array}{l}\text { Debilitamiento de la integridad } \\
\text { de los mercados financieros }\end{array}$ & 75 & 46,01 \\
$\begin{array}{l}\text { Pérdida de control de la política } \\
\text { económica }\end{array}$ & 31 & 19,02 \\
Pérdida de rentas públicas & 57 & 34,97 \\
\hline Total & 163 & $100 \%$ \\
Fuente: Elaboración propia & &
\end{tabular}




\section{DISCUSIÓN}

En la investigación se arribó que el 60,12\% de las Cooperativas no han implementado las medidas correctivas del FENACREP. Existe una coincidencia con la tesis de Fuster y Verástegui (2018) quienes afirman que las reglas para prevenir el lavado y la subvención de los que causan el terror deben ser aplicables en el peritaje contable, contribuyendo a identificar los principales casos de este delito en la cooperativa de Ahorros y Créditos del Perú. La aplicación de normas legales vigentes en materia periciales y la aplicación del nuevo código procesal Penal y la internacionalización de la profesión contable, conlleva a formular, enriquecer y presentar una propuesta concertada sobre la adecuación del marco normativo para la actuación, en materia de pericia contable frente al lavado activo. De esta manera, no existe una legislación integral, completa y eficiente, que permita el control de tráfico ilícito de drogas y el lavado de activos o de dinero. El 57,67\% de las Cooperativas expresan que las principales causas de lavado de activos son la falta de supervisión de parte de FENACREP. También hay una similitud con la tesis de Cabello (2017) quien mostró que los delitos más congregados son: en primer lugar, la compra de propiedades cuyo monto vital oscila en un $80 \%$ con origen desconocido, y estos sirvieron para las compras de propiedades en el año 2015. Finalmente, la investigación concluye que para los procesos de auditoría en la actualidad son tradicionales, los cuales no obtienen resultados claros, es necesario una reingeniería en sus procesos así contribuirá con la transparencia en la administración pública de todas las regiones.

\section{REFERENCIAS BIBLIOGRÁFICAS}

Armienta, G., Goite, M., Medina, A., Gambino, L., \& García, L. (2015). Lavado de dinero en el siglo XXI, una visión desde los instrumentos jurídicos internacionales, la doctrina y las leyes en América Latina y España. México, D.F.: Editorial Unijuris. Recuperado de: http:// www.pensamientopenal.com.ar/system/files/2016/02/ doctrina42906.pdf
Cano, M. (2015). Auditoria forense en la investigación criminal de lavado de dinero y de activos. (2da. ed.). Bogotá: Editorial Ecoe.

Cabello, V. (2017). Peritaje Financiero vinculada al delito de lavado de activos en la Sala Penal Nacional, 2013-2016. (Tesis de maestría). Universidad César Vallejo, Lima.

Carnelutti, F. (1980). La Prueba Civil. Buenos Aires, Argentina: Ediciones Arayú.

Huayllani, H. (2016). El delito previo en el delito de lavado de activos. (Tesis de maestría). Pontificia Universidad Católica del Perú, Lima.

Lamas, L. (2015). Inteligencia financiera y operaciones sospechosas. Lima: Editorial Gaceta Jurídica.

Ramírez, E. (1992). El proceder del perito contable en los aspectos técnicos y legales del campo judicial. (Tesis de pregrado). Universidad San Martin de Porras, Lima.

Ramírez, J. y Ruiz, M. (2018). Propuesta de un Programa de Auditoría Forense para prevenir y detectar delitos de corrupción en los procesos logísticos de la Municipalidad Provincial de Chiclayo. (Tesis de maestría). Universidad Pedro Ruiz Gallo, Lambayeque.

Rolando, R. (2005). Lavado de Activos en el Perú y a nivel mundial. Lima: Librería y Ediciones Jurídicas.

Ruiz, A. (2013). El Peritaje Contable Judicial frente a la corrupción: doctrina legislación, jurisprudencia (2da. ed.). Lima: Talleres gráficos de ARS Asesoría y Servicios.

Ugarte, J. (2014). Panorama de la inteligencia criminal latinoamericana. Desarrollo, dilemas y dificultades. URVIO: Revista Latinoamericana de Estudios de Seguridad, (15), 41 - 54. Recuperado de: https://revistas. flacsoandes.edu.ec/urvio/article/view/1586

Fuster, J. \& Verástegui, J. (2018). La pericia contable frente al lavado de activos en las cooperativas de ahorro $y$ crédito del Perú en el periodo 2018. (Tesis de maestría). Universidad Nacional Daniel Alcides Carrión, Pasco. 
